\section{Allopurinol-induced severe cutaneous adverse reactions}

In their article entitled 'Insights into the poor prognosis of allopurinol-induced severe cutaneous adverse reactions: the impact of renal insufficiency, high plasma levels of oxypurinol and granulysin', ${ }^{1}$ Chung and colleagues elegantly investigated the factors associated with severe cutaneous adverse reactions (SCAR) in patients taking allopurinol as antihyperuricaemic agent and found that impaired renal function and increased plasma levels of oxypurinol and granulysin correlated with the poor prognosis of allopurinol SCAR. In their results section, the authors stated that they did not find any difference in patients with renal impairment in the values of initial dose/estimated glomerular filtration rate (eGFR) between allopurinol SCAR and tolerant controls. This result seems in contrast to what reported by Stamp et $a l^{2}$ because these authors found that there was an increase in the risk of allopurinol SCAR as the starting dose of allopurinol corrected for the estimated GFR increased. The main difference between these two studies is that the mean baseline eGFR was frankly lower in the cohort studied by Chung $\left(34 \mathrm{~mL} / \mathrm{min} / 1.73 \mathrm{~m}^{2}\right)$ compared with the cohort studied by Stamp $\left(50.2 \mathrm{~mL} / \mathrm{min} / 1.73 \mathrm{~m}^{2}\right)$. In both studies, the Modification Diet Renal Disease (MDRD) study equation was used to calculate eGFR. Two important questions should then be answered. (1) Is the initial dose/eGFR negligible in terms of risk of SCAR in patients with more severe renal impairment? (2) Was the group of patients studied by Chung dialysis-free? Unfortunately in the text it is not specified whether the patients were dialysisfree and as plasma oxypurinol concentrations are reduced by $50 \%$ by dialysis, ${ }^{3}$ this could be of great importance in the final results.

\section{Corrado Campochiaro}

Correspondence to Dr Corrado Campochiaro, IRCCS San Raffaele, Unit of Internal Medicine and Clinical Immunology, Milan 20132, Italy; corradocampochiaro@gmail. com

Citation: Chung WH, Chang WC, Stocker SL, et al. Insights into the poor prognosis of allopurinol-induced severe cutaneous adverse reactions: the impact of renal insufficiency, high plasma levels of oxypurinol and granulysin. Ann Rheum Dis 2015;74:2157-64.

Competing interests None declared.

Provenance and peer review Not commissioned; internally peer reviewed.

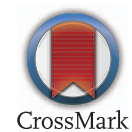

To cite Campochiaro C. Ann Rheum Dis 2016;75:e20.

Accepted 31 December 2015

Published Online First 19 January 2016

\section{STinked}

- http://dx.doi.org/10.1136/annrheumdis-2015-209109

Ann Rheum Dis 2016;75:e20. doi:10.1136/annrheumdis-2015-209108

\section{REFERENCES}

1 Chung WH, Chang WC, Stocker SL, et al. Insights into the poor prognosis of allopurinol-induced severe cutaneous adverse reactions: the impact of renal insufficiency, high plasma levels of oxypurinol and granulysin. Ann Rheum Dis 2015;74:2157-64.

2 Stamp LK, Taylor WJ, Jones PB, et al. Starting dose is a risk factor for allopurinol hypersensitivity syndrome: a proposed safe starting dose of allopurinol. Arthritis Rheum 2012;64:2529-36.

3 Day RO, Kannangara DR, Hayes JM, et al. Successful use of allopurinol in a patient on dialysis. BMJ Case Rep 2012;2012:pii: bcr0220125814. 